\title{
Host recognition and possible imprinting in the anemonefish Amphiprion melanopus (Pisces: Pomacentridae)
}

\author{
Michael Arvedlund ${ }^{1, *}$, Mark I. McCormick ${ }^{1}$, Daphne G. Fautin ${ }^{2}$, Mogens Bildsøe $^{3}$ \\ ${ }^{1}$ Department of Marine Biology, James Cook University, Townsville, Queensland, Australia \\ ${ }^{2}$ University of Kansas, Biological Sciences and Natural History Museum, Lawrence, Kansas 66045-2106, USA \\ ${ }^{3}$ Department of Animal Behaviour, ZoologicaI Institute, University of Copenhagen, 2100 Copenhagen OE, Denmark
}

\begin{abstract}
Many reef fish have strong microhabitat preferences when they settle to the juvenile population, and choices at this time may influence fish survival. This is exemplified in anemonefishes (Family: Pomacentridae) that exhibit obligate symbiotic relationships with a restricted range of sea anemone species. This study examined how juvenile anemonefish Amphiprion melanopus select their host, and whether recognition and selection are mediated by an imprinting-like mechanism. Specifically, we experimentally examined the host-selection made by $A$. melanopus that had been reared under constant conditions, but whose embryos had received 1 of 3 treatments: (1) in contact with a known natural host sea anemone, Entacmaea quadricolor $;(2)$ in contact with the sea anemone Heteractis malu, which is not a host for $A$. melanopus in nature, but is a host for anemonefish of other species; and (3) without a sea anemone (or chemical cues released from sea anemones) at any life stage. Our study shows that olfaction, not vision, is used by juvenile $A$. melanopus to recognize host anemones. Furthermore, the choice of a settlement site for juvenile $A$. melanopus is strongly influenced by events that occur early in development, prior to the dispersal of larvae from their natal site. We suggest that juvenile $A$. melanopus possess an innate preference for $E$. quadricolor, a preference that is enhanced by imprinting. Interestingly, it was not possible to imprint $A$. melanopus larvae to the non-host sea anemone $H$. malu, which suggests that anemonefish host-imprinting may be rather restricted.
\end{abstract}

KEY WORDS: Chemotaxis - Host-imprinting - Fish larvae settlement - Habitat recognition - Sea anemones $\cdot$ Symbiosis

\section{INTRODUCTION}

Symbiotic relationships between fishes and cnidarians have been recorded in temperate (Dahl 1961, Mansueti 1963, Elliott 1992), subtropical (Abel 1960, Mansueti 1963) and tropical waters (Mansueti 1963, Stevenson 1963, Colin \& Heiser 1973, Smith 1973, Allen 1975, Gendron \& Mayzel 1976, Hanlon \& Kaufman 1976, Hanlon et. al 1983, Hanlon \& Hixon 1986). The association that has received the most attention is that between anemonefishes of the genera Amphi.

- Present address: Raadhusvaenget 14, 1. Floor, 3600 Frederikssund, Denmark. E-mail: michaelarvedlund@hotmail.com prion and Premnas and their host sea anemones of the genera Stichodactyla, Heteractis, Entacmaea, Macrodactyla, and Cryptodendrum (e.g. Mariscal 1966, Fricke 1974, Allen 1975, Dunn 1981, Fautin 1991, Elliott \& Mariscal 1997). The highly specific nature of the anemonefishes' habitat requirements at settlement, and the importance of recruitment for the maintenance of adult populations, have focused research on the problems of host recognition by newiy settling juveniles (Fricke 1974, Miyagawa \& Hidaka 1980, Murata et al. 1986, Miyagawa 1989, Konno et al. 1990, Elliott et al. 1995, Arvedlund \& Nielsen 1996). This research has shown for several species of juvenile anemonefishes that olfactory cues released from the sea anemone enable the juveniles to recognize a suitable host. 
Miyagawa (1989) and Fautin (1991) discussed the hypothetical possibility that anemonefish embryos, which develop in egg cases beside the anemone in which the parent fish live (Allen 1975), may imprint to olfactory cues (synomones sensu Murata et al. 1986) released from the host anemone. Arvedlund \& Nielsen (1996) experimentally demonstrated that Amphiprion acellaris imprints on its host anemone Heteractis magnifica. Imprinting may work in conjunction with a genetically determined predisposition for selection of anemones of a particular suite, which governs which hosts are selected by juvenile anemonefishes at settlement.

Acquired recognition of a particular object is known in many species of birds, where exposure to an object during a sensitive period early in life causes an intense change in the animals' behaviour towards this object later in life (review in Bolhuis 1991). This behaviour was initially described by Konrad Lorenz and labelled imprinting (Lorenz 1935, 1937). Apart from avian species, imprinting has also been demonstrated to take place in fishes, as for instance in salmon species that show an astounding competence for returning to the same river they left as juveniles (Hasler \& Scholz 1983). Today, at least 3 different types of imprinting are recognised (Immelman 1972, 1975a,b, Immelman \& Suomi 1981): filial, sexual and ecological. Filial imprinting is the type described above and reviewed by e.g. Bolhuis (1991). Sexual imprinting has mainly been shown in birds and involves the establishment of sexual preferences by means of social contact with the (foster) parents or (foster) siblings during a comparatively brief period during juvenile life (review in e.g Immelmann 1972). Ecological imprinting is concerned with the establishment of food and habitat preferences selection of a home area and host selection in parasitic animals (review in e.g. Immelmann 1975a), by means of being raised on a restricted diet as a juvenile, or by means of contact with a particular habitat or host. Anemonefish host-imprinting belongs to this last category. The criteria for ecological imprinting follow the criteria for classical imprinting according to Immelmann (1975a). Classical (filial) imprinting has 4 criteria (Lorenz 1935): (1) It can take place only during a restricted time of the individual's life, the sensitive period. (2) It is irreversible. (3) It involves the learning of supra-individual, species-specific characteristics. (4) It may be completed at a time when the appropriate reaction itself is not yet performed.

To further explore the role of host-imprinting in anemonefish we did experiments that addressed whether and how imprinting affects host choice by settling juveniles. Our study used anemonefish of the species Amphiprion melanopus, which is symbiotic primarily with the clonal morph of the anemone Entac- maea quadricolor, and less frequently with the anemones Heteractis crispa and $H$. magnifica. All occur sympatrically on the Great Barrier Reef (Dunn 1981, Fautin 1986, Fautin \& Allen 1992, Srivinasan 1997. Arvedlund pers. obs.). Our experiments addressed 3 questions: (1) Are visual or chemical cues used by $A$. melanopus juveniles in host recognition? (2) Is imprinting important in the recognition and selection of suitable host anemones by $A$. melanopus juveniles? (3) Is it possible to imprint $A$. melanopus juveniles on species of anemones with which they do not associate in nature?

We experimentally investigated the host-selection made by Amphiprion melanopus that had been reared under constant conditions, but whose embryos had received 1 of 3 treatments: (1) in contact with a known natural host sea anemone, Entacmaea quadricolor (abbreviated: $A m-E q$ ); (2) in contact with the sea anemone Heteractis malu that is not a host for A. melanopus in nature, but is a host for anemonefish of other species (Am-Hmalu); and (3) without a sea anemone (or chemical cues released from sea anemones) at any life stage (Am-).

\section{METHODS}

\section{Animal maintenance and rearing of Amphiprion} melanopus. Breeding pairs of Amphiprion melanopus were collected from the northern Great Barrier Reef, Australia, and placed in $60 \mathrm{l}$ tanks with gravel filters and $200 \mathrm{l}$ powerheads for the circulation of water. The tanks were filled with filtered coastal water from the James Cook University (JCU) closed aquarium system (Job et al. 1997), with $33 \%$ salinity, a temperature of 27 to $28^{\circ} \mathrm{C}$ and a $\mathrm{pH}$ of 8.0 to 8.2 . Half of the water for experimental arrays Am-Eq and Am-Hmalu was changed every second day with clean marine water from the JCU system. JCU system water is filtered through sand and large protein skimmers, so we believe olfactory compounds originating from anemones would be, at most, only a natural 'background noise' Breeding pairs without anemones ( $A m$-) were kept in tanks isolated from the main system, each tank having its own separate carbon filtration. These tanks were filled with coastal water filtered to $1 \mu \mathrm{m}$, and $50 \%$ of the water in the tank was replaced with new coastal water, which was filtered to $1 \mu \mathrm{m}$ every second day. Rocks were placed in all tanks as a surface on which the fish could spawn. Tanks were illuminated on a 14:10 h light:dark cycle, with 3 blue actinic tubes (420 nm) and 1 daylight tube. The wavelengths produced maximum growth of the anemone's zooxanthellae, which helped keep the anemones in good condition. Sea anemones often bleached after a few months 
in captivity. Only anemones with good brown colouration, an indicator of good condition (Arvedlund pers. obs.), were used in the experiments. Sea anemones of the species Entacmaea quadricolor, Heteractis crispa, $H$. magnifica, and $H$. malu were collected from the northern Great Barrier Reef and held outdoors in flowthrough $250 \mathrm{l}$ tanks at the JCU aquarium facility until used in experiments.

The general experimental breeding setup involved female Amphiprion melanopus, which laid a clutch of eggs on a rock beside a specimen of host anemone. During development of the embryos and hatching, the host anemone was present, close beside the embryos in the egg cases. In treatment $A m-E q$, the anemone was Entacmaea quadricolor. In Am-Hmalu, the anemone was Heteractis malu. In the third treatment, $A m$-, the mother fish laid eggs on a rock in the tank without an anemone. In this treatment, although the parent fish had lived with an anemone previously, there was no anemone in the tank during the course of the experiment, and water in tanks was ensured to be completely free of suspected sea anemone odours. Five different pairs of $A$. melanopus were used for each type of treatment. All treatments were isolated from one another at all times.

Anemonefish embryos hatched in other $60 \mathrm{l}$ tanks in which the water was gently aerated. The water was not filtered since the fish larvae are sensitive to current (Arvedlund pers. obs.). The sides of these tanks were covered with black plastic to reduce light reflection. The phytoplankter Nannochloropsis sp. was used to 'green up' the tanks until the bottom of the tank could not be seen. These methods of reducing light from directions other than above stopped the 'headbutting syndrome' of the fish larvae and improved water quality, since the algae act as a nutrient sink (Job et al. 1997).

Spawning, which occurred approximately every 3 wk produced 200 to 300 eggs per clutch. Embryos hatched in 9 d. An hour or two before hatching, the rock with the egg clutch and the sea anemone was transferred in a water-filled bucket to the hatching aquarium, where the clutch was left for approximately $90 \mathrm{~min}$ in the dark. The hatching aquarium was pre-filled with 51 of water from the parental aquarium. The anemone was removed from the hatching aquarium $30 \mathrm{~min}$ after the embryos had hatched. For $A m-$, the tank was topped up with water from the parental tank, and then $50 \%$ of the water was changed daily with water from the parental tank to ensure constant osmolarity. This procedure ensures the best survival rate of the fish larvae, which lack the ability to osmoregulate (Arvedlund pers. obs.). For the other types of batches, the tank was topped up with water from the JCU system, i.e. $50 \%$ of the water in the hatching tank on the night of hatching came from the parental tank, to ensure constant osmolarity for the fish larvae, and $50 \%$ came from the system. The aquarium was aerated, and $50 \%$ of the water was replaced every day starting from the first day after hatching with water from the JCU system. We are aware that by this method the fish larvae might have been contaminated with a low solution of synomones on the first day after hatching. However, this procedure was necessary in order to avoid total loss of larvae due to lack of ability to osmoregulate (Arvedlund \& Nielsen 1996, Arvedlund pers. obs.).

The larvae were fed the rotifer Brachionus plicatilis for $2 \mathrm{~d}$ after hatching, and were then gradually

\section{A Visual versus chemical cues}

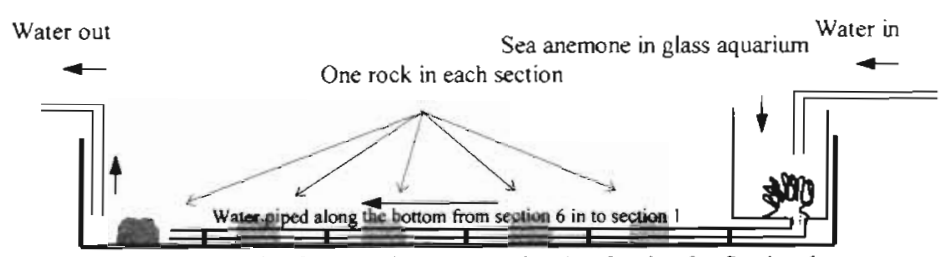

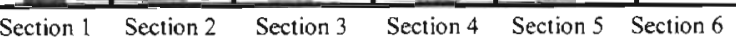

B Chemical cues

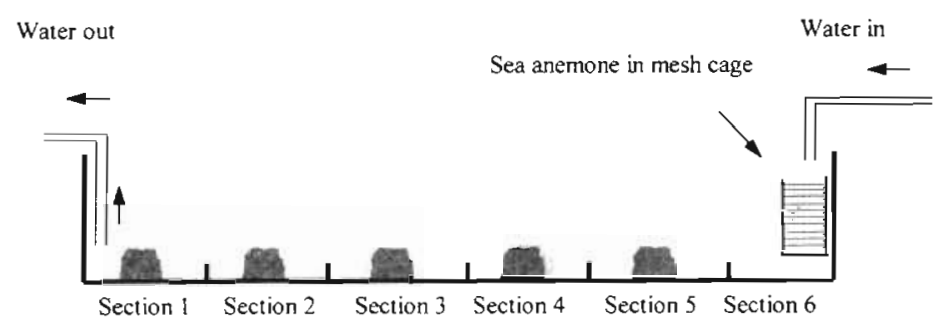

C

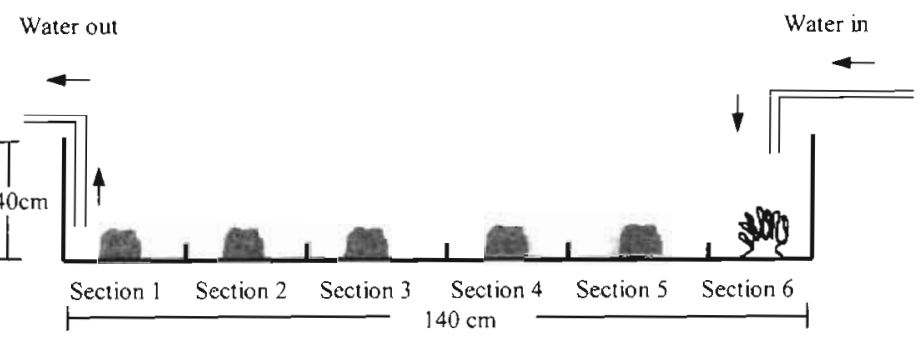

Fig. 1. Experimental setup, to determine whether visual or chemical cues are used by juvenile Amphiprion melanopus to detect sea anemones of various species 
switched to Artemia. After approximately $30 \mathrm{~d}$, the juveniles were gradually switched to the adult diet of finely chopped sardines, prawns, and vitamin supplements. An average of $70 \%$ of the embryos survived to the juvenile stage. Larvae from each batch, i.e. from each parent, were kept isolated from the other batches prior to their use in experiments. Five fish were chosen randomiy from each batch for 1 test. Only fish from the same batch, i.e. same parents, were used for 1 test.

Experimental regime. Three series of experiments were conducted with a protocol generally similar to that of Miyagawa (1989) and Arvedlund \& Nielsen (1996). Modifications were as follows. An aquarium measuring $140 \times 40 \times 40 \mathrm{~cm}$ was marked lengthwise to form 6 sections of equal size (Fig. 1), which allowed the fish to be tracked easily. Water in the test aquarium was circulated at a rate of 100 to $110 \mathrm{l}$ $\mathrm{h}^{-1}$ through a carbon filter to maintain a gradient of odours in the tank. The carbon was replaced every 8th experiment. Before each trial, the 5 fish used were restricted to section 1 (section 5 for experiments, Fig. 1A) by a removable glass plate for $240 \mathrm{~min}$ to allow acclimation to the test aquarium. Once the fish were acclimated, the glass plate was removed and the positions of the 5 fish were recorded manually once every half minute for $60 \mathrm{~min}$. The test aquarium was cleaned thoroughly with fresh water and filtered seawater was replaced after each experiment. For all trials, 5 fish aged 30 to $150 \mathrm{~d}$ were tested at once. Juveniles younger than $30 \mathrm{~d}$ and solitary juveniles are easily stressed, which led to irregular behaviour in preliminary observations (Arvedlund pers. obs.). We are aware that this age is older than the age of anemonefish larvae settling on the reef (Allen 1975). No fish was used more than once for an experiment, so all fish used were naïve. Control trials for all experiments were performed with the 3 types of Amphiprion melanopus which were selected in random order.

(Fig. 1A) Visual versus chemical cues: To gauge the relative importance of visual and olfactory cues to juveniles that had been reared with Entacmaea quadricolor ( $A m-E q)$, fish were presented with visual cues from E. quadricolor at one end of the test tank (section 6), and olfactory cues from $E$. quadricolor at the other (section 1). An anemone was placed in a small glass aquarium $(20 \times 22 \times 25 \mathrm{~cm})$ at the inflow end of the test aquarium (section 6 ). Water that flowed into the anemone aquarium at the top was piped out through the bottom of the aquarium to section 1 , at the far end of the main aquarium, by way of a plastic hose. The water level in the main tank was below the top of the small aquarium. No anemone was in the small tank in the control tests.
(Fig. 1B) Chemical cues alone: An anemone was placed at the inflow end of the aquarium (section 6 ) in a cage $(12 \times 10 \times 25 \mathrm{~cm})$ of green vinyl $5 \mathrm{~mm}$ mesh. To prevent the anemone being observed by the fish, the cage was wrapped in 2 layers of gauze. Anemones were allowed to acclimate in the cage for 2 to $3 \mathrm{~h}$ (depending on size) before each trial. Due to the small size of Entacmaea quadricolor, 2 to 3 specimens were placed in the cage for each trial. The fish's behaviour, such as nibbling the cage, was recorded. In control trials, no anemone was present in the cage.

(Fig. 1C) Visual and chemical cues: An anemone was placed in the inflow section of the test tank (section 6) without barriers to water flow or vision. For trials with Entacmaea quadricolor, 3 to 4 anemone specimens were used for each experiment.

Statistical analyses. A Wilcoxon's signed-rank test (Zar 1996) was used to test whether the fish in each trial were randomly distributed in the aquarium in relation to a hypothetical median (equal to the center of the test aquarium), or whether they were significantly attracted to (or deterred by) one end of the aquarium. The test is suitable for these kind of experiments, as long as the observations are independent, i.e not autocorrelated. In guppies Poecilia reticulata, which have a size distribution and activity level similar to the juvenile anemonefishes used in this study, intervals of $15 \mathrm{~s}$ produced positions that were not autocorrelated (Bildsøe \& Sørensen 1994). To be on the safe side, a 30 s time interval was used in the present study. At times, between the observations, the fish swam back and forth from one end of the test tank to the other in less than $30 \mathrm{~s}$. Therefore, we can safely assume that successive observations were indeed independent. Observations of the position of the 5 fishes were conducted 120 times, i.e. over a period of $1 \mathrm{~h}$, for each experiment. The average position of the 5 fish once every $30 \mathrm{~s}, X$, was calculated using the position of the 5 fish as follows:

$$
X=\frac{0.5 A+1.5 B+2.5 C+3.5 D+4.5 E+5.5 F}{5}
$$

The letters $A$ to $F$ represent the cumulative number of fish observed in each of 120 observations made in each section of the tank. The 120 calculated $X$-values in each experiment was used: (1) to calculate the median for each trial to compare with the hypothetical median, and (2) for graphical presentation. The significance level of the test was 0.05 .

For Expt C (visual and chemical cues), the number of fish (if any) that acclimated to the anemone at the end of the observation period, as well as with the time taken for the furst fish to begin acclimation behaviour, were recorded. 
Table 1. Results from Expt A, visual versus chemical stimuli. Wilcoxon's signed-rank test (test for location) was performed to obtain the calculated median $\left(\tilde{x}_{C}\right)$ and the sum of observations on each side of the hypothetical median $\left(\widetilde{x}_{H}\right) . \widetilde{x}_{H}=2.5$

\begin{tabular}{|c|c|c|c|c|c|c|}
\hline & \multicolumn{3}{|c|}{$\begin{array}{l}\text { Sum of observations } \\
x<\widetilde{x}_{H} \quad x=\widetilde{x}_{H} \quad x>\widetilde{x}_{H}\end{array}$} & $\begin{array}{l}\text { Calculated } \\
\bar{x}_{C}\end{array}$ & d p & $\begin{array}{l}\text { No. of } \\
\text { 'kisses' }\end{array}$ \\
\hline \multicolumn{7}{|c|}{$\begin{array}{l}\text { Fish rearing code: Am-Eq } \\
\text { mpty glass aquarium }\end{array}$} \\
\hline Trial 1 & 49 & 6 & 65 & 2.7 & 0.067 & 0 \\
\hline Trial 2 & 64 & 11 & 45 & 2.5 & 0.692 & 0 \\
\hline Trial 3 & 50 & 15 & 55 & 2.5 & 0.396 & 0 \\
\hline Trial 4 & 63 & 14 & 43 & 2.3 & 0.194 & 0 \\
\hline Trial 5 & 58 & 6 & 56 & 2.5 & 0.403 & 0 \\
\hline \multicolumn{7}{|c|}{$\begin{array}{l}\text { (B) Test: host sea anemone Entacmaea quadricolor in } \\
\text { glass aquarium }\end{array}$} \\
\hline Trial 1 & 120 & 0 & 0 & 1.3 & $\ll 0.05$ & 0 \\
\hline Trial 2 & 61 & 7 & 52 & 2.3 & $<0.05$ & 0 \\
\hline Trial 3 & 113 & 2 & 5 & 1.5 & $\ll 0.05$ & 35 \\
\hline Trial 4 & 104 & 3 & 13 & 0.7 & $\ll 0.05$ & 0 \\
\hline Trial 5 & 105 & 3 & 12 & 1.2 & $\ll 0.05$ & 24 \\
\hline
\end{tabular}

\section{RESULTS}

\section{Expt A Visual versus chemical cues}

In all control trials, fish spent equal amounts of time in all sections. No attention was paid to the small tank (Table 1A). A different behaviour was observed in the trials with a host in the small tank (Table 1B). Once released, after acclimation to the test tank in section 5, fish swam to section 1 and remained there. This occurred in all 5 trials and 'kissing' (touching with the mouth) of the hose outlet was observed in trials 3 and 5 (Table 1). On several occasions, fish suddenly swam in a rapid zig-zag manner toward section 1, where the water from the anemone was released.

\section{Expt B Chemical cues}

In 3 control trials, fish spent a significant amount of time of the trial period nearer section 1 . In the remaining 2 control trials, the fish spent equal time in all sections (Table 2A). Am-Eq was used in trials with either Entacmaea quadricolor or Heteractis magnifica (Table 2BC, Fig. 3BC). Within minutes of being released from section 1 , fish swam quickly toward the mesh cage containing E. quadricolor. On several accasions, juveniles 'kissed' the mesh cage with their mouths (Table 2B). In general, fish remained close to the mesh cage throughout the 60 min test period. Am-Eq juveniles placed in the test tank with a specimen of $H$. magnifica in the mesh cage were not attracted to the cage (Table $2 \mathrm{C}$ ). Fish showed either a slight tendency toward section 1 (the release end of the test tank), or were evenly distributed throughout the tank. To test whether fish were simply attracted to the visual stimulus of the mesh cage, 5 control trials were run. In the controls, Am-Eq juveniles showed a preference for section 1 , the end of the tank where they had been released (Table 2A). Three trials of Am-Hmalu with E. quadricolor in the mesh cage showed the same pattern as for $A m-E q$ : they swam to the cage and stayed near it, occasionally 'kissing' it (Table 2D). The opposite results were obtained in the last 2 trials, with the fish spending most of the obseryation period in section 1 (Table 2D). When the anemone in the mesh cage was $H$. crispa, fish in all 5 trials remained mainly in the sections of the test aquarium furthest from the cage, and no 'kissing' was observed (Table 2E). When the anemone $H$. malu was used in trials with AmHmalu juveniles, fish stayed in sections 1 and 2 of the aquarium (Table 2F) and no 'kisses' were recorded. Similarly, juveniles Am-tested with E. quadricolor (Table 2G) stayed mainly in sections 1 to 3 of the test aquarium and no 'kisses' were observed.
$\mathbf{A}$
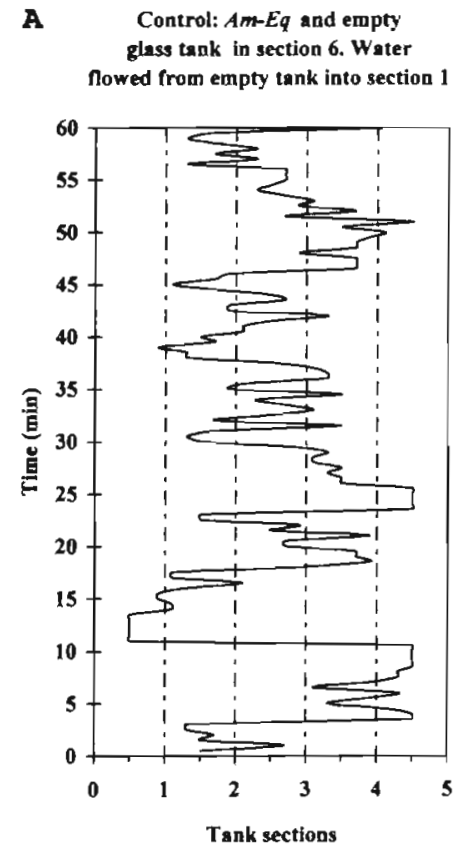

B Am-Eq and the host anemone
E.quadricolor in glass tank in section 6. Water
flowed from tank with anemone into section 1

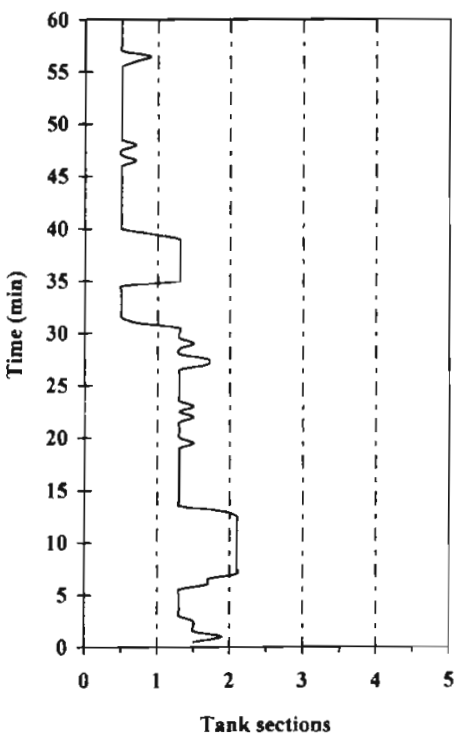

Fig. 2. Examples of the calculated average position for 5 juveniles of $A m-E q$ during 60 min of observation in Expt A (chemical stimuli in section 1 and visual stimuli in section 6, from which the fish were excluded; Fig. 1A). (A) Control. (B) One experimental trial 


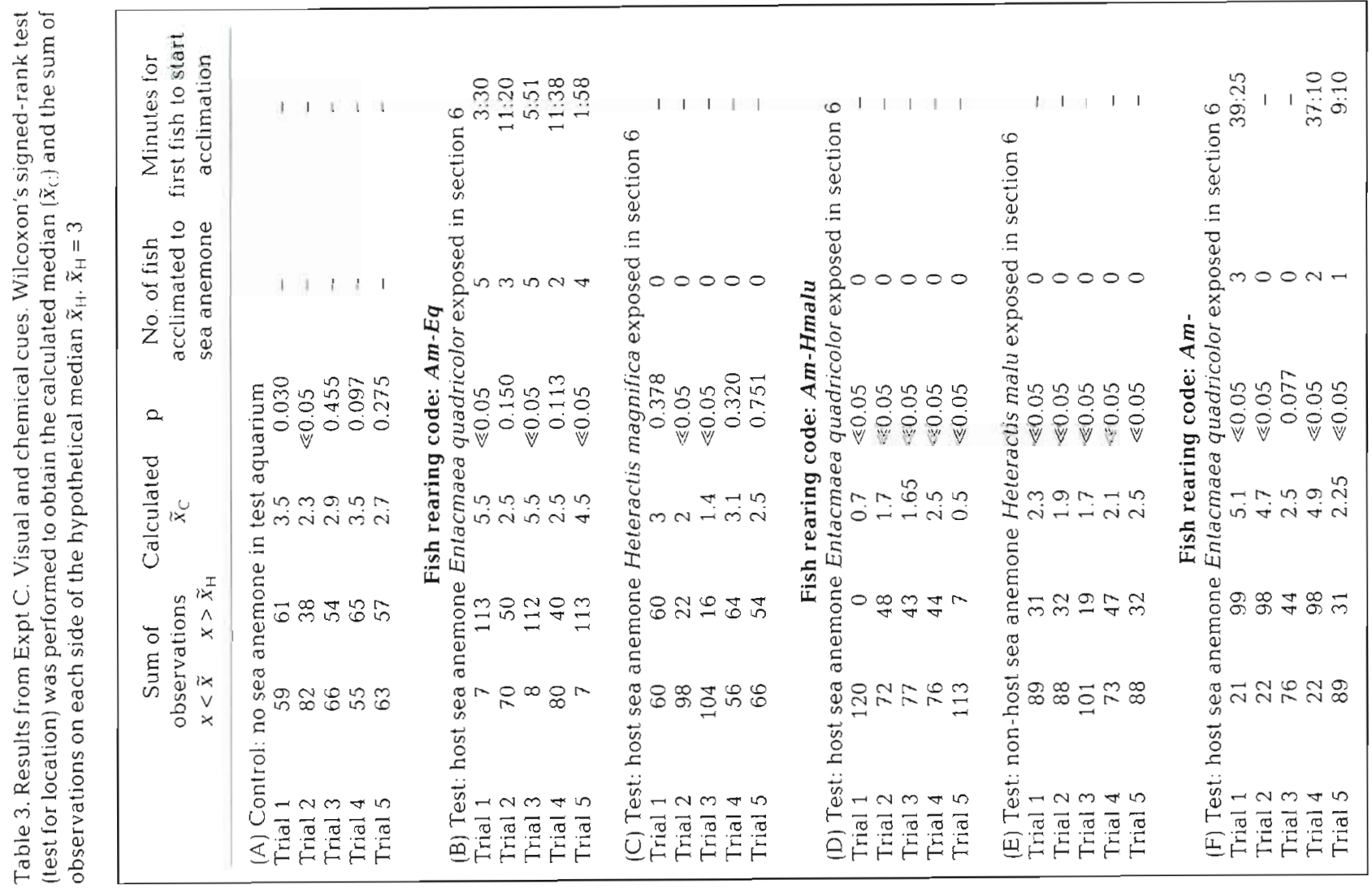

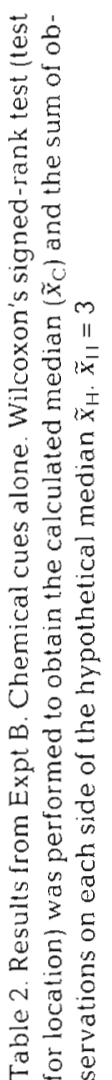

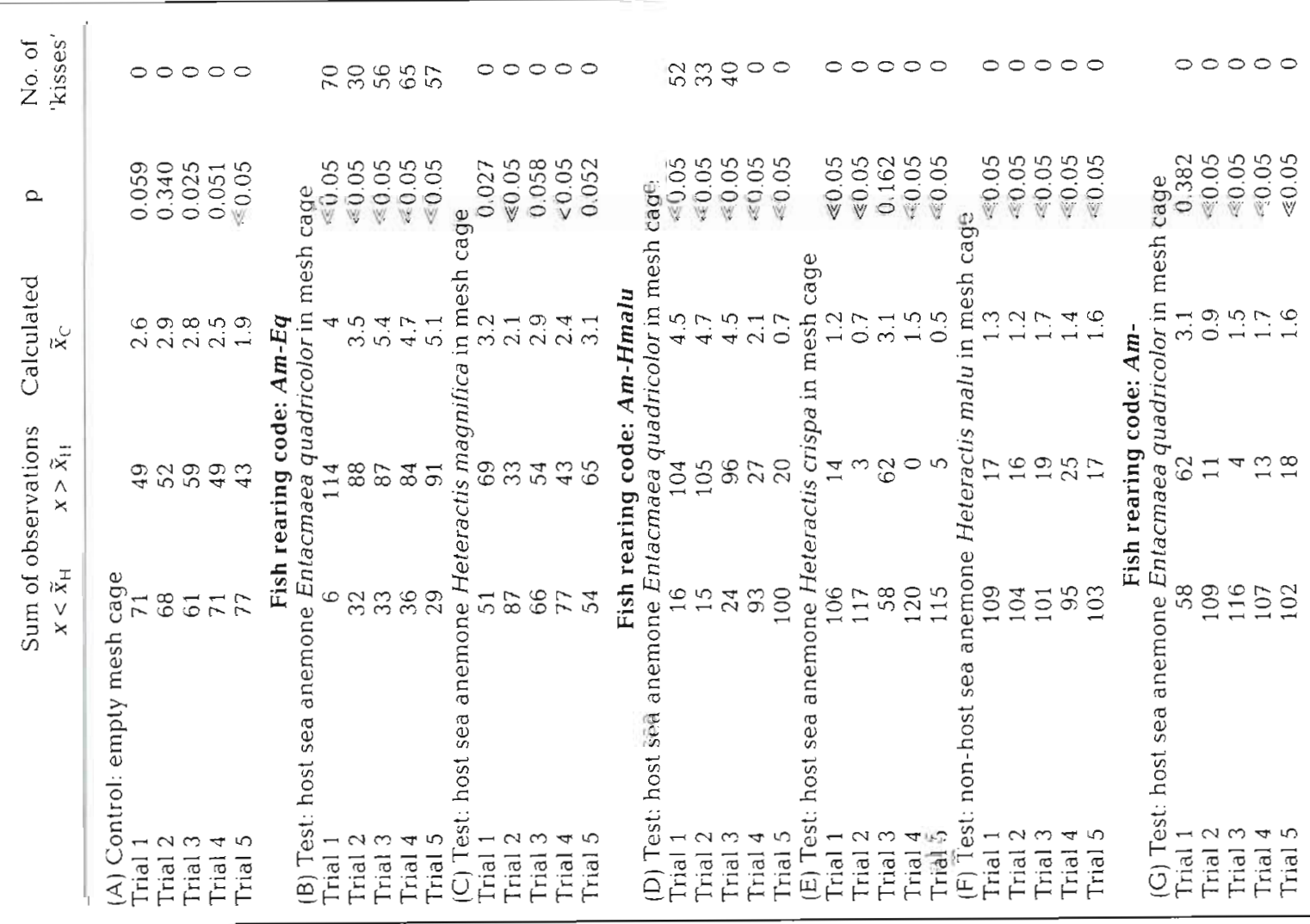


A Control: $A m-E q$ and empry cage

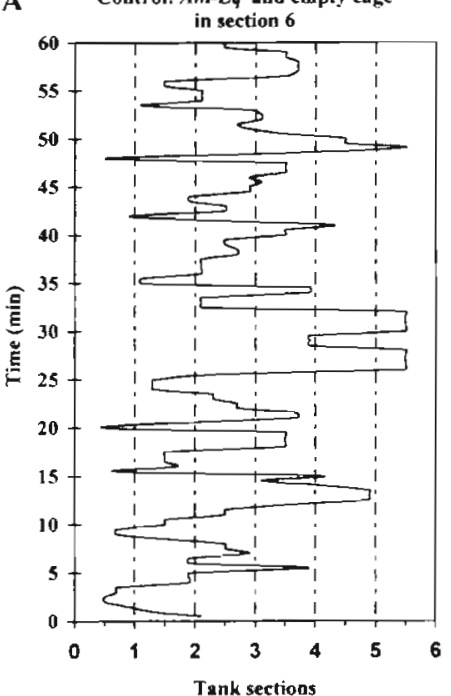

D Am-Hmalu and the host sea anemone

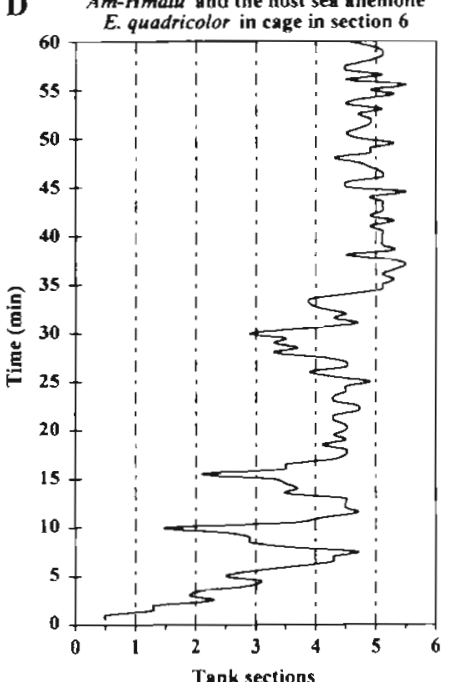

G Am-and the host sea anemone

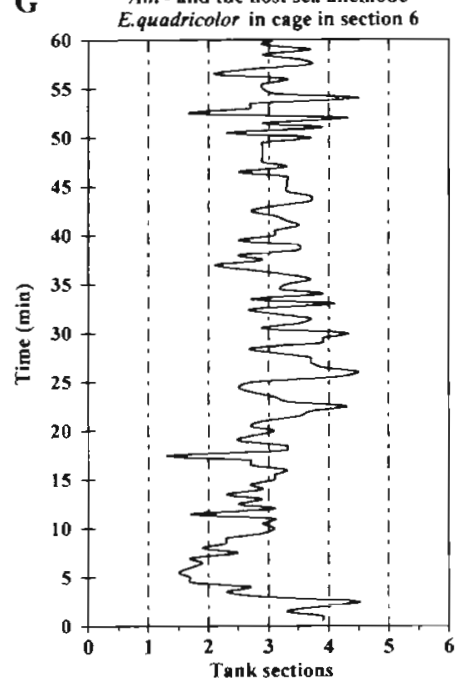

B

B Am-Eq and the host sea anemone

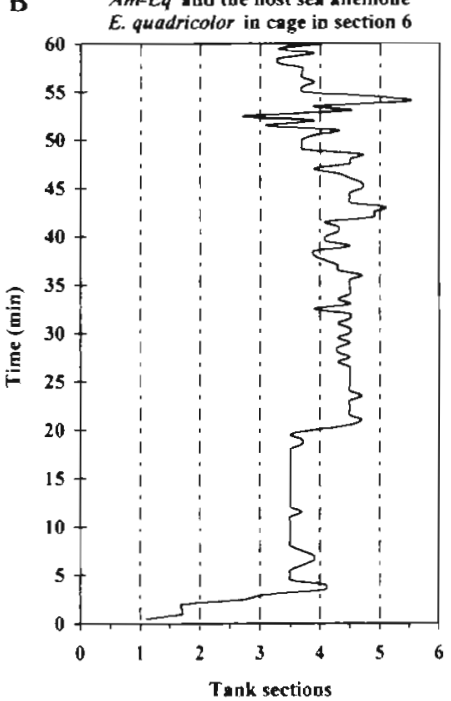

E Am-Hmalu and the host sea anemone

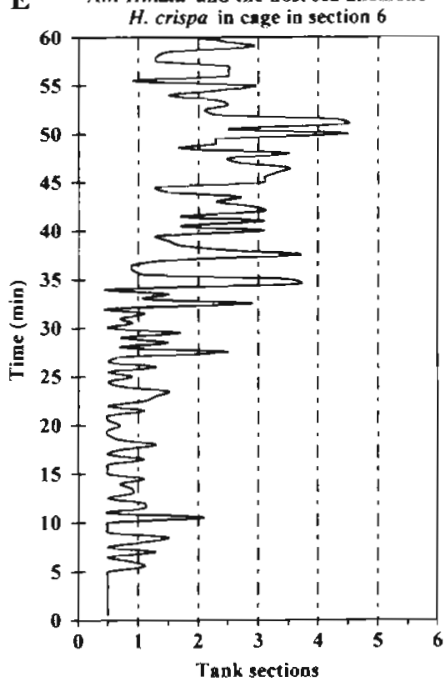

C $\quad A m-E q$ and the host sea anemone
$H$. magnifica in cage in section 6

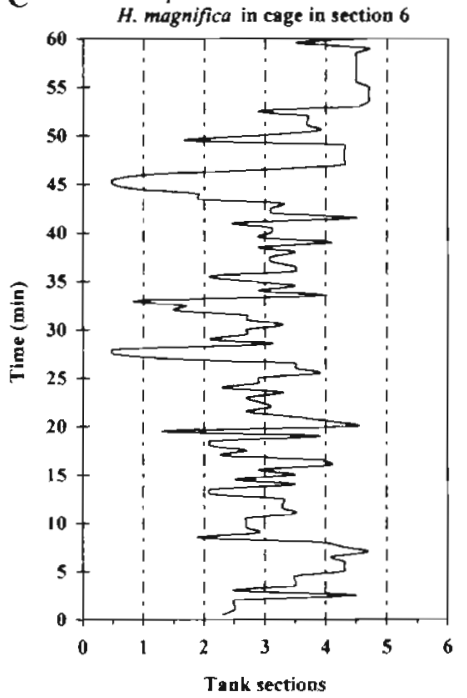

F Am-Hmalu and the non-host sea anemone

A $m$-Hmolu and the non-host sea ane
$H$. malu in cage in section 6

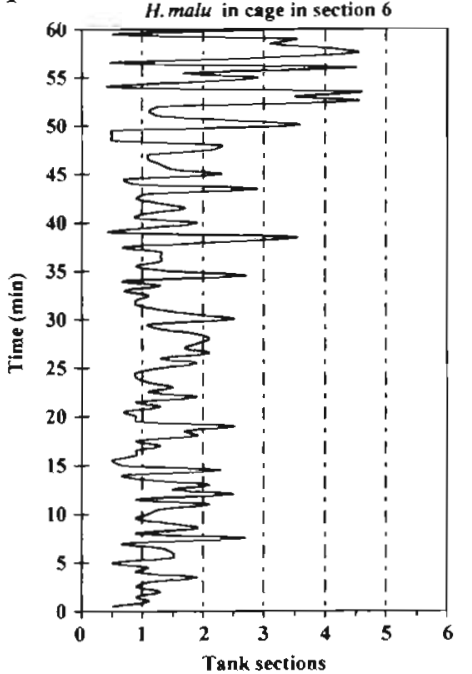

Fig. 3. Examples of the calculated average position for 5 juveniles of ( $A$ to $C$ ) $A m-E q$, (D to F) Am-Hmalu and (G) Am-1 during 60 min of observation in response to sea anemone odours emanating from section 6 (A is a control trial) 
A

Control: $A m-E q$ and nothing in section 6

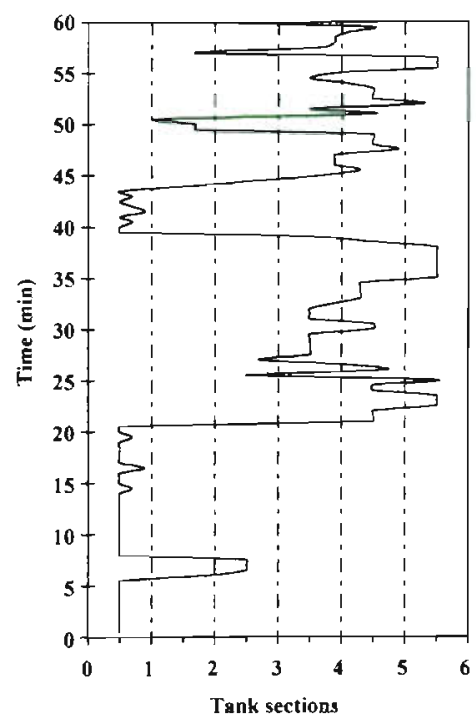

D

Am-Hmalu and the non-host sea anemone $H$. malu exposed in section 6

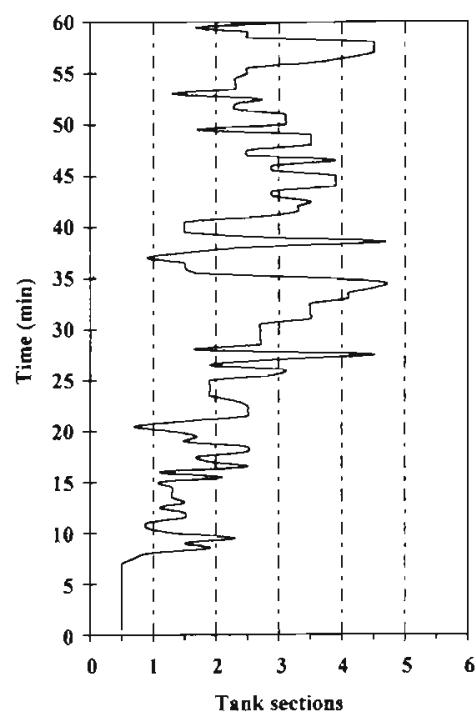

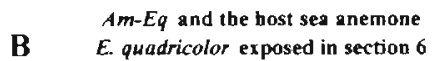

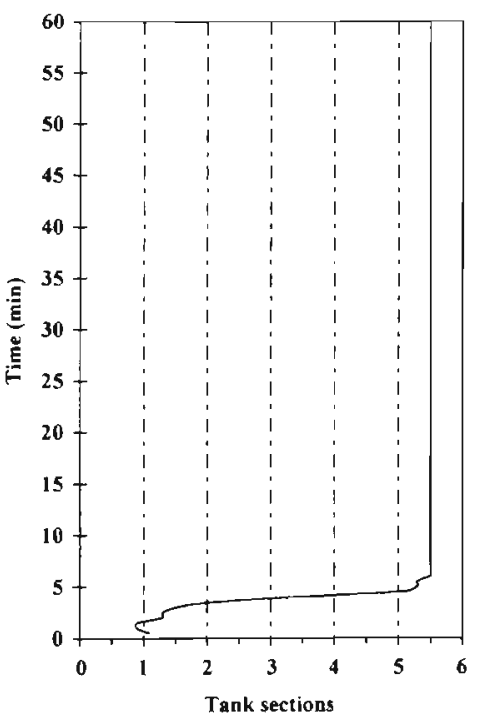

Am-Hmalu and the host sea anemone E E. quadricolor exposed in section 6

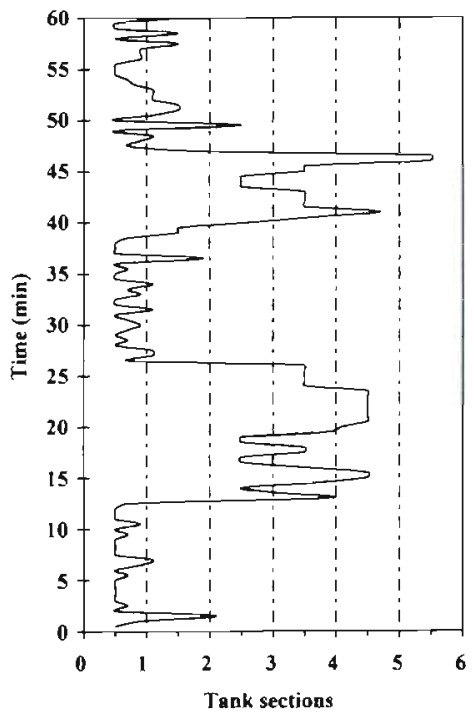

Am-Eq and the host sea anemone
H.magnifica exposed in section 6

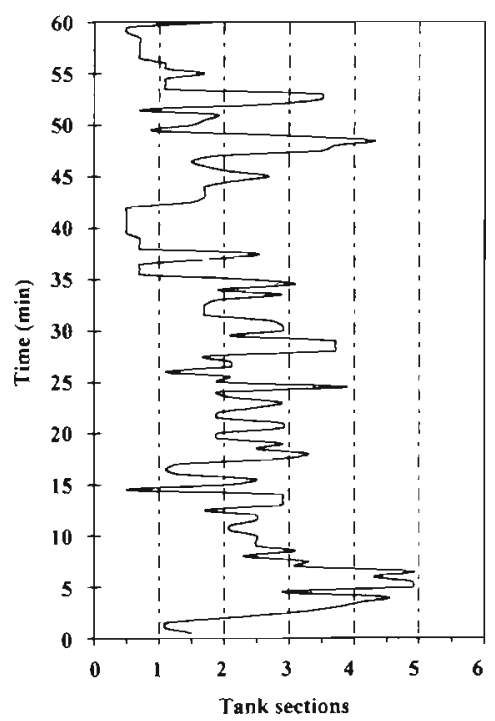

Am- and the host anemone F E. quadricolor exposed in section 6

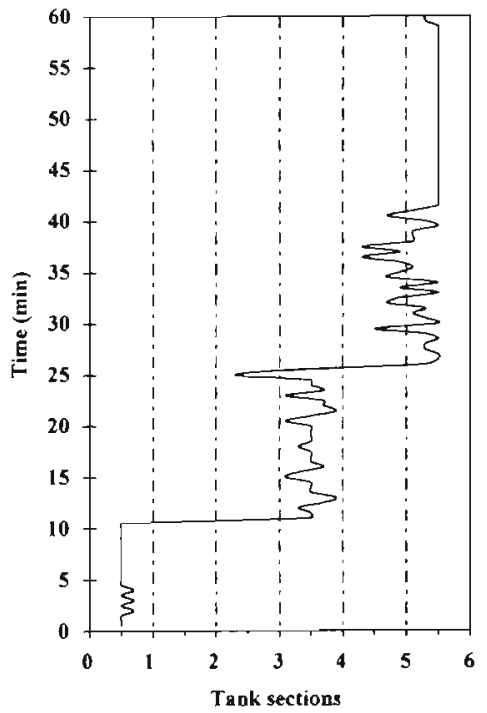

Fig. 4. Examples of the calculated average position of 5 juveniles of (A to C) $A m-E m,(D, E) A m-H m a l u$, and (F) Am-during 60 min of observation in response to a sea anemone in section 6 ( $A$ is a control trial)

\section{Expt $C$ Visual and chemical cues}

In all control trials, the fish spent a significant amount of time during the test sections nearer 1 (Table 3A). Tested with Entacmaea quadricolor, Am-Eq fish swam quickly toward section 6 , where the anemones were. Most fish showed a significant attraction to the anemone (Table 3B). Within 12 min of reaching the test anemone, the fish started the process of acclimation to their host (see Elliott \& Mariscal 1997 for a comprehen- sive definition of acclimation). A fish acclimated by first hovering above the anemone's tentacles for 5 to $10 \mathrm{~s}$, then slowly lowering its abdomen into the tentacles for 5 to $10 \mathrm{~s}$. When the fish was completely covered by tentacles, it stayed 1 min before moving around in the anemone. The mean time for the first fish in the group to acclimate was $6 \min 51 \mathrm{~s}$ (Table $3 \mathrm{~B}$ ). Am-Eq tested with the host anemone Heteractis magnifica showed no attraction to the anemone (Table 3C). No fish acclimated and in none of the trials did a fish 
spend a significant amount of time in sections near the anemone. Am-Hmalu fish were not attracted to either E. quadricolor or $H$. malu (Table 3D,E). Fish remained mainly in sections 1 to 3 of the test aquarium, and no attempts to acclimate were observed. In 3 of the 5 trials (1,2, and 4), Am- fish spent significantly more time in aquarium sections near the anemone, and in trials 1,4 , and 5 a few fish acclimated to the anemone (Table $3 F$ ). The mean time for the first fish in the group to acclimate was $28 \mathrm{~min} 35 \mathrm{~s}$. Fish did not acclimate to the hosts in trials 2 and 3 , despite spending significantly more time in sections 5 and 6 than in other sections (Table 3F).

\section{DISCUSSION}

Juvenile Amphiprion melanopus that had undergone embryonic development near Entacmaea quadricolor $(A m-E q)$ used olfaction rather than vision to recognize their host anemone E. quadricolor. Our observation of sudden zig-zag swimming toward the hose outlet is consistent with tracking a water-borne cue. The findings that $A m-E q$ are chemically but not visually attracted to their host anemone are similar to results obtained by Fricke (1974), Miyagawa \& Hidaka (1980), Miyagawa (1989), and Arvedlund \& Nielsen (1996), who conducted experiments with anemonefish other than A. melanopus, and support the findings of Elliott et al. (1995) with $A$. melanopus in field experiments

Juvenile $A m-E q$ recognized their host anemone Entacmaea quadricolor by olfactory cues, but could not recognize the less frequently inhabited host anemone Heteractis magnifica using olfaction. The same pattern was observed when $A m-E q$ was presented to specimens of these 2 host anemones that were not hidden: fish rapidly acclimated to $E$. quadricolor, but they did not recognize $H$. magnifica. Of Am-Hmalu juveniles, $60 \%$ were attracted to odours from the host anemone E. quadricolor, while none were attracted to the less frequently inhabited host anemone $H$. crispa. The $40 \%$ of Am-Hmalu, which were not attracted to the host anemone $E$. quadricolor, along with the remaining $60 \%$, demonstrates a weak genetic disposition for the odours from the host E. quadricolor: when presented to an exposed specimen of $E$. quadricolor, there was no recognition. Am-juveniles were not attracted to odours from a caged E. quadricolor, but were to an exposed host anemone of that species, to which they managed to acclimate. However, Am-showed significantly weaker ability than $A m-E q$ to recognize this host anemone.

These results suggest that Amphiprion melanopus may be imprinting on Entacmaea quadricolor. Imprinting may reinforce the fish's innate ability to recognize
E. quadricolor, which can be disrupted under some conditions, as shown in our experiments ( $A m$ - and $A m$ Hmalu). These findings are similar to the results of Arvedlund \& Nielsen (1996) for the anemonefish $A$. ocellaris, which appears to imprint on its host anemone Heteractis magnifica, as well as having a genetic predisposition for olfactory recognition of this anemone. We further conclude that the innate ability of $A$. melanopus to recognize its host anemone works for $E$. quadricolor, but not for the less frequently inhabited host $H$. crispa.

Juvenile anemonefish Am-Hmalu that passed through embryological development beside an anemone of that species did not imprint to Heteractis malu. Am-Hmalu did not recognize olfactory cues from this anemone, nor did the fish acclimate to this anemone. This finding has ramifications for the understanding of the complicated specificity patterns between anemonefishes and their hosts. Fautin (1986) and Fautin \& Allen (1992) suggested that 3 different factors affect specificity between anemonefishes and their hosts: (1) fish have an innate or learned imprinting preference for only some of the anemones potentially available for colonization; (2) interspecific competition between the fishes; (3) chance. If anemonefish imprinting is a restricted mechanism, it may be of minor importance in explaining host specificity patterns. Our findings may also help in explaining a recent observation of unusual host specificity patterns in the Seychelles. Two species of anemonefishes are represented there, Amphiprion akallopisos with the host $H$. magnifica, and A. fuscocaudatus with the hosts $H$. magnifica, Entacmaea quadricolour, H. aurora and Stichodactyla mertensii (see den Hartog 1997). A striking observation by den Hartog (1997) was that anemonefish did not associate with the host anemone $H$. crispa, the most common host anemone in the Seychelles, along with $\mathrm{H}$. magnifica. Elsewhere in its geographic range a variety of Amphiprion spp. commonly associate with this anemone (Fautin \& Allen 1992). Restricted imprinting could be the explanation. From an evolutionary perspective, anemonefish host-imprinting may be a very young mechanism which is still evolving, since it has not taken advantage of extra habitat resources for the anemonefish species that occur in the Seychelles.

We infer that imprinting is weaker in Amphiprion melanopus than in $A$. ocellaris, because individuals of $A$. ocellaris reared without an anemone did not acclimate to their host anemone Heteractis magnifica until $48 \mathrm{~h}$ after the start of the experiment. Am- started to acclimate on average after $28 \min 35 \mathrm{~s}$. We therefore suggest that $A$. melanopus may have a stronger innate recognition of its main host than does $A$. ocellaris. On this basis we infer that imprinting in $A$. melanopus is more restricted than it is in the known cases of salmon 
(see reviews by Hasler \& Scholtz 1983, Quinn \& Dittman 1992, Dittman \& Quinn 1996) and birds (reviewed by Bolhuis 1991). It is possible to imprint salmon to artificial chemical compounds (Tilson et al. 1994, 1995), and birds to humans (Lorenz 1935).

\section{The proposed imprinting phenomenon: is it 'classical' imprinting?}

Is our suggested anemonefish host-imprinting compatible with Lorenz's (1935) classical definitions of imprinting? The anemonefish host-imprinting phenomenon is ecological host-imprinting (Immelmann 1975a,b, Immelman \& Suomi 1981), and follows Lorenz's (1935) criteria as stated in our introduction.

As for Lorenz's first criterion, imprinting in anemonefishes must occur between the fertilization of the eggs and the time when the newly hatched larvae leave the nest. It may occur by diffusion or active uptake of chemicals from the anemone through the egg surface to the developing embryo, or after hatching, by contact of the larvae with anemone mucus. The timing of imprinting in embryos of the anemonefishes could be examined by removing the embryos on different days from the host anemone and testing the juveniles for imprinting. Our findings suggest that imprinting does occur during a restricted time in the fishes' life. However, it is presently unclear whether the embryo stage is the only life stage sensitive to synomones, since in our experiments there were low concentrations of synomones in the first $24 \mathrm{~h}$ after the hatching of Am-.

Anemonefishes do not appear to lose the ability to recognize odours from their host anemone, which supports Lorenz's second criterion for imprinting. We found that juvenile Am-Eq as old as $150 \mathrm{~d}$ still recognized odours from a visually obscured host anemone Entacmaea quadricolor. This supports the findings of Arvedlund \& Nielsen (1996), who conducted long-term laboratory experiments involving host recognition by Amphiprion ocellaris reared with the host anemone Heteractis magnifica. Naïve, 18 mo-old fish acclimated to this host in only $5 \mathrm{~min}$. Miyagawa (1989) found similar results with other anemonefish species. However, this is not quite the same as Lorenz's definition of irreversibility. To prove irreversibility we would have to take an older juvenile and force it to live with a nonselected host, then test its selectivity once acclimated to the new host. If, when given a choice between an ecologically imprinted host and the forced host, it chose the former, we would then have irreversibility. We suggest that our demonstrated response may be irreversible, but have to emphasize that this has not been demonstrated in our study.
Lorenz's third criterion for imprinting involves the learning of supra-individual, species-specific characteristics, i.e. a certain degree of generalization. This has been shown by Arvedlund \& Nielsen (1996) for Amphiprion ocellaris, and for A. melanopus in this study. Both species were imprinted to one specimen of host, and later recognized a different host specimen of the same species in repeated experiments.

The last of Lorenz's (1935) criteria for imprinting also seems to hold for anemonefishes. The acquired ability to detect a particular host is completed at a time (as an embryo and/or right after hatching) when the appropriate reaction itself has not yet been performed (imprinting is not important until settlement).

Is anemonefish host-imprinting then compatible with Lorenz's classical imprinting? Since criteria 1 and 2 remain unanswered, we cannot yet determine whether classical (although host, not filial) imprinting occurs in Amphiprion melanopus and A. ocellaris. We suggest that future studies concentrate on answering the first 2 of Lorenz's criteria.

We have shown that rearing conditions influence anemonefish host choice at settlement. Our study demonstrates the importance of maternal effects in the recruitment dynamics of anemonefishes through imprinting on the host. We therefore suggest that investigations of settlement preferences in anemonefishes (as well as other reef fishes) make detailed note of the rearing conditions (including the host, if one is present) to aid in the interpretation of results.

Our study has ramifications for the interpretation of settlement in other reef fish species. Many fishes have strong microhabitat associations, and these microhabitats are known to have a complex influence on recruitment patterns (e.g. Sale et al. 1984, Eckert 1985, Breitburg 1991, Levin 1991, Harmelin-Vivien et al. 1995, McCormick \& Makey 1997). Imprinting to specific microhabitats (such as corals) may occur for species other than anemonefishes that also have restricted microhabitat settlement. Sweatman (1988) showed that the settling damselfish larvae of Dascyllus aruanus and $D$. reticulatus recognize their microhabitat by chemical cues released by resident adult conspecifics. The possibility of imprinting exists.

Acknowledgements. We thank Suresh Job for considerable help and advice with the rearing of the anemonefishes and comments to the manuscript. John Morrison has also contributed with great help to the construction of the rearing facilities. Thanks to David R. Bellwood for valuable suggestions in the early phase of this study. Also thanks to Richard Rowe and Joel Elliott for constructive suggestions for improvements of the manuscript. This study is part of M. A.'s PhD disser. tation conducted at James Cook University and was made possible by doctoral grant no. 1995-154-0080 from the Danish Research Academy, Aarhus, Denmark. 


\section{LITERATURE CITED}

Abel EF (1960) Liaison facultative d'un poisson (Gobius buchichii Steindacner) et d'une anémone (Anemonia sulcata Peen) en Mediteranée. Vie Milieu 11:517-531

Allen GR (1975) The anemonefishes. Their classification and biology, 2nd edn. TFH Publ, Neptune City, NJ

Arvedlund Mr Nielsen LE (1996) Do the anemonefish Amphiprion ocellaris (Pisces: Pomacentridae) imprint themselves to their host sea anemone Heteractis magnifica (Anthozoa: Actinidae)? Ethology 102:197-211

Bildsøe M, Sorensen JB (1994) A method of modelling time dependent data: swimming in guppies (Poecilia reticulata) under threat of a predator. Behav Proc 31:75-96

Bolhuis JJ (1991) Mechanisms of avian imprinting: a review. Biol Rev 66:303-345

Breitburg DL (1991) Settlement patterns and presettlement behaviour of the naked goby, Gobiosoma bosci, a temperate oyster reef fish. Mar Biol 109:213-222

Colin PB, Heiser JB (1973) Associations of 2 species of cardinalfishes (Apogonidae: Pisces) with sea anemones in the West Indies. Bull Mar Sci 23:521-524

Dahl E (1961) The association between young whiting, Gadus merlangus, and the jellyfish Cyanea capillata. Sarsia 3: $47-55$

den Hartog JC (1997) Notes on the genus Amphiprion Bloch \& Schneider, 1801 (Teleostei: Pomacentridae) and its host sea anemones in the Seychelles. Zool Med Leiden 71 $182-188$

Dittman AH, Quinn TP (1996) Homing in Pacific salmon: mechanisms and ecological basis. J Exp Biol 199:83-91

Dunn DF (1981) The clownfish sea anemones. Stichodactylidae (Coelenterata:Actinaria) and other sea anemones symbiotic with pomacentrid fishes. Trans Am Phil Soc $71(1): 1-115$

Eckert GJ (1985) Settlement of coral fishes to different natural substrata and at different depths. Proc 5th Coral Reef Congr 5:385-390

Elliott $J$ (1992) The role of sea anemones as refuges and feeding habitats for the temperate fish Oxylebius pictus. Environ Biol Fish 35:381-400

Elliott J, Mariscal RN (1997) Acclimation or innate protection of anemonefishes from sea anemones? Copeia 1997 2: $284-289$

Elliott J, Elliott JM, Mariscal RN (1995) Host selection, location, and association behaviors of anemonefishes in field settlement experiments. Mar Biol 122:377-389

Fautin DG (1986) Why do anemonefishes inhabit only some host actinians? Environ Biol Fish 15(3):171-180

Fautin DG (1991) The anemonefish symbiosis: what is known and what is not. Symbiosis 10:23-46

Fautin DG, Allen GR (1992) Field guide to anemonefishes and their host sea anemones, 1st edn. Western Australian Museum, Perth

Fricke HW (1974) Öko-Ethologie des monogamen Anemonenfisches Amphiprion bicinctus. Z Tierpsychol 36:429-512

Gendron RP, Mayzel K (1976) Association of Thalasssoma bifasciatum with Condylactis gigantea in the Bahamas. Copeia 1976:382-384

Hanlon RT, Hixon RF (1986) Behavioral associations of coral reef fishes with the sea anemone Condylactis gigantea in Dry Tortugas, Florida. Bull Mar Sci 39(1):130-134

Hanlon RT, Kaufman L (1976) Associations of seven West Indian reef fishes with sea anemones. Bull Mar Sci 33: 225-232

Hanlon RT, Hixon RF, Smith DG (1983) Behavioral associations of seven West Indian reef fishes with sea anemones at Bonaire, Meshherlands Antilles. Bull Mar Sci 26:928-934

Harmelin-Vivien ML, Harmelin JG, Leboulleux U (1995) Microhabitat requirements for settlement of juvenile sparid fishes on Mediterranean rocky shores. Hydrobiologia 301:309-320

Hasler AD, Scholtz AT (1983) Olfactory imprinting and homing in salmon, 1st edn. Springer-Verlag, Berlin

Immelman K (1972) Sexual and other long-term aspects of imprinting in birds and other species. Adv Study Behav $4: 147-174$

Immelman K (1975a) Ecological significance of imprinting and early learning. Annu Rev Ecol Syst 6:15-37

Immelman $\mathrm{K}$ (1975b) The evolutionary significance of early experience. In: Baerends G, Beer C, Manning A (eds) Function and evolution in behaviour. Clarendon Press, Oxford, p 244-253

Immelman K, Suomi SJ (1981) Sensitive phases in development. In: Immelman K, Barlow GW, Petrinovich L, Main M (eds) Behavioral development. The Bielefeld Interdisciplinary Project. Cambridge University Press, Cambridge, p $395-431$

Job S, Arvedlund M, Marnane MJ (1997) Culture of coral reef fishes. Austasia Aquacult 11(3):56-59

Konno K, Qin G, Nakanishi K (1990) Synthesis of amphikuemin and analogs: a synomone that mediates partnerrecognition between anemonefish and sea anemones. Heterocycles $30(1): 247-251$

Levin PS (1991) Effects of microhabitat on recruitment variation in a Gulf of Maine reef fish. Mar Ecol Prog Ser 75: $183-189$

Lorenz K (1935) Der Kumpan in der Umwelt des Vogels. J Orn $83: 137-213 ; 289-4.13$

Lorenz K (1937) The companion in the bird's world. Auk 54 245-273

Mansueti R (1963) Symbiotic behavior between small fishes and jellyfishes, with new data on that between the stromateid, Peprilus alepidotus, and the scyphomedusa, Chrysara quinquecirrha. Copeia 1963(1):40-80

Mariscal RN (1966) The symbiosis between tropical sea anemones and fishes: a review. In: Bowman RI (ed) The Galapagos: Proceedings of the Symposia of the Gal Int Scient Proj University of California Press, California, p 157-171

McCormick MI, Makey LJ (1997) Post-settlement transition in coral reef fishes: overlooked complexity in niche shifts. Mar Ecol Prog Ser 153:247-257

Miyagawa K (1989) Experimental analysis of the symbiosis between anemonefishes and sea anemones. Ethology 80 $19-46$

Miyagawa K. Hidaka T (1980) Amphiprion clarkij juvenile innate protection against and chemical attraction by symbiotic sea anemones. Proc Jpn Acad 56(B):356-361

Murata M, Miyagawa-Kohshima K, Nakanishi K, Naya $Y$, (1986) Characterisation of compounds that induce symbiosis between sea anemone and anemonefish. Science 234 : $585-587$

Nordlund AD, Lewis WJ (1976) Terminology of chemical releasing stimuli in intraspecific and interspecific interactions. J Chem Ecol 2 (2):211-220

Quinn TP, Dittman AH (1992) Fishes. In: Papi F (ed) Animal homing. Chapman \& Hall, London, p 145-211

Sale PF, Douglas WA, Doherty PJ (1984) Choice of microhabitats by coral reef fishes at settlement. Coral Reefs 3 : 91-99

Smith WL (1973) Records of a fish associated with a Caribbean sea anemone. Copeia 1973(3):597-598

Srivinasan M (1997) Ecology and life-histories of anemonfishes: a multi-scale study ofpatterns and processes. BSc 
thesis, Department of Marine Biology, James Cook University, Townsville

Stevenson RA (1963) Behavior of the pomacentrid reef fish Dascyllus albisella Gill in relation to the anemone Marcanthia cookei. Copeia 1963 (3):612-614

Sweatman $\mathrm{H}$ (1988) Field evidence that settling coral reef fish larvae detect resident fishes using dissolved chemical cues. J Exp Mar Biol Ecol 124:163-174

Tilson MB, Scholtz AT, White RJ, Galloway H (1994) Thyroidinduced chemical imprinting in early life stages and

Editorial responsibility: Otto Kinne (Editor),

Oldendorf/Luhe, Germany assessment of smoltification in kokanee salmon hatcheries. 1993 Annual Report. Prepared for Bonneville Power Administration. Portland, Oregon

Tilson MB, Scholtz AT, White RJ, Hendrickson JL (1995) Artificial imprinting and smoltification in juvenile kokanee salmon: implications for operating Lake Roosevelt kokanee salmon hatcheries. 1994 Annual Report. Prepared for Bonneville Power Administration. Portland, Oregon

Zar JH (1996) Biostatistical analysis, 3rd edn. Prentice-Hall Inc, Upper Saddle River, NJ

Submitted: February 2, 1999; Accepted: August 8, 1999 Proofs received from author(s): September 29, 1999 